\title{
Evaluation of IFN- $\gamma$ production in bovine hypodermosis using ELISPOT and ELISA
}

Eva Cabanelas, Ceferino Lopez, Pablo Diaz, Ana Perez-Creo, Maria Patrocinio Morrondo, Pablo Diez-Banos and Rosario Panadero*

*Correspondence: rosario.panadero@usc.es

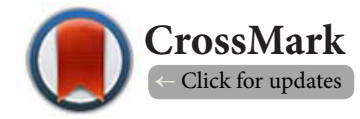

Department of Animal Pathology, Animal Health (INVESAGA group), Veterinary school, University of Santiago de Compostela, Lugo, Spain.

\begin{abstract}
Background: Two enzyme immunoassays, ELISPOT and sandwich ELISA, were compared in order to evaluate the production of interferon gamma (IFN- $\gamma$ ) in peripheral blood mononuclear cell (PBMC) cultures from Hypoderma (Diptera: Oestridae) infested cattle.

Methods: Cell cultures from Hypoderma-infested (sensitized) and uninfested cattle (non-sensitized) were stimulated with the mitogen phytohemaglutinin A (PHA) and with different $H$. lineatum antigens, crude larval extract (CLE) and its purified fractions (hypodermin A, B and C). IFN- $\gamma$ secreting cells (SC) were detected using an ELISPOT test, whereas theIFN- $\gamma$ levels presented in supernatants from parallel cell cultures were measured by a sandwich ELISA; the same bovine specific IFN- $\gamma$ antibodies were employed in both tests.

Results: The addition of H. lineatum antigens had an immunomodulatory effect on PBMC cells from both infested and uninfested cattle, characterized by suppression in the production of IFN- $\gamma$. ELISPOT results showed that hypodermin B was the antigen with major immunosuppressive effect on non-sensitized cultures, while CLE had the strongest impact on previously sensitized cultures. Our results revealed that the ELISPOT showed a high sensitivity allowing the determination of IFN- $\gamma-\mathrm{SC}$ frequencies in non-stimulated cultures; in contrast, the sandwich ELISA was not useful for detecting IFN- $\gamma$ levels in parallel culture supernatants.

Conclusion: The ELISPOT test allows an accurately determination of the frequency of IFN- $\gamma$-SC in $e x$ vivo PBMCs without the need for extensive re-stimulation in vitro with antigen or mitogen over long periods of time.

Keywords: Cattle-arthropoda, hypoderma, IFN- $\gamma$, ELISPOT, ELISA, cellular responses

Warble flies (Hypodermabovis, L. and Hypoderma-lineatum, De Villers) cause myiasis in cattle from the Northern Hemisphere, leading to a serious negative impact on animal productivity and welfare. Newly-hatched larvae penetrate the skin aided by the secretion of enzymes from the parasites' midgut (hypodermins A, B and C). Then, they migrate through fascial planes of muscles and connective tissue to the oesophageal submucosa, where they over winter before migrating to, and eventually completing their development in, the subdermal tissues of the back [1]. Larval secretions are also implicated in immunomodulatory processes, allowing the survival of the

It is well known that young cattle are the most susceptible

to Hypoderma infestation, since old cattle develop acquired resistance after repeated exposures to Hypoderma larval antigens [3]. This resistance has been recognized as an important factor in controlling larval populations, depending on both the host age and the number of larvae invading the host [4].

Interferon-gamma (IFN- $\gamma$ ), secreted by Th1-type cells, plays an important role in the activation of cell-mediated immunity. It is also considered as the main cytokine implicated in both the activation of phagocytic cells and the production of some IgG sub classes from B cells. This cytokine is produced predominantly by natural killer and natural killer T cells as part of the innate immune response, and by Th1 CD4 and CD8 cytotoxic $T$ lymphocyte effector $T$ cells after the development of antigenspecific immunity [5].
\end{abstract}

\section{Introduction} parasite [2]. 
The profile of production of this cytokine during the course of hypodermosis was investigated in previous studies by sandwich enzyme-linked immunosorbent assay (ELISA) with variable results. In naturally infested cattle, a significant reduction on IFN- $\gamma$ serum levels during the resting phase of $H$. lineatum larvae in the oesophagus was observed by sandwich ELISA [7]. In contrast, in experimentally infested cattle IFN- $\gamma$ serum levels remained below the detection limit of the test $(1 \mathrm{ng} / \mathrm{ml})$ during larvae penetration [6], although immune histochemistry results showed a significant increase of the number of IFN- $\gamma^{+}$cells detected in the skin.

The enzyme-linked immunospot assay (ELISPOT) has demonstrated to be highly sensitive for the ex vivo quantification of cytokine-secreting cells after in vitro stimulation with an antigen [8]. In addition, while ELISA shows the final cytokine concentration without revealing the number and rate of cytokine-secreting cells, ELISPOT shows the frequency of antigen specific T-cells [9].

In this study, an ELISPOT assay for the detection of IFN- $\gamma$ secreting cells (SC) was developed in order to study the immunomodulatory effect of $H$. lineatum larval antigens in both previously sensitized and non-sensitized cattle peripheral blood mononuclear cells (PBMCs). The frequencies of IFN- $\gamma$-SC detected by ELISPOT and the levels of IFN- $\gamma$ in culture supernatants measured by sandwich ELISA were also compared.

\section{Material and methods}

\section{Animals and PBMC collection}

Four Frisian cows (4-8 years old) that presented warbles on their back were used in this study as previously sensitized cell donors. Apart from Hypoderma infestation, those animals were apparently healthy. Four Frisian calves (6-8 months old), without previous contact with the parasite, were chosen as non-sensitized cell donors.

Blood samples were collected in heparinised tubes by caudal venipuncture and PBMCs were individually isolated by density gradient centrifugation using Ficoll solution (specific gravidity $1.077 \mathrm{~g} / \mathrm{ml}$, Biochrome AG) according to a previous study [10]. Viability of cells was determined by Trypan Blue dye exclusion, considering valid a percentage above $90 \%$.

\section{Antigen preparation}

The antigens used in this study were prepared from $\mathrm{H}$. lineatum first instar larvae (L-1) collected from oesophagi of cattle slaughtered in a local abattoir. Larvae were homogenized with a Polytron tissue homogenizer (Kinematica AG), using 0.1M Tris- $\mathrm{HCl} \mathrm{pH} 7.5$ buffer. The homogenate was centrifuged at $10.000 \mathrm{rpm}$ for 5 minutes and the supernatant, that constituted the crude larval extract (CLE), was collected. Hypodermins A, $B$ and $C$ were after wards purified by ion-exchange chromatography, using diethylamino etil (DEAE)-cellulose (DE-52, Whatman) as anion exchanger. After the dialysis of the different fractions, the purity of the hypodermins was tested by sodium dodecyl sulfate polyacrylamide gel electrophoresis
(SDS-PAGE) in reduced conditions. The protein concentration for each antigen was determined by the bicinchoninic method (BCA Protein Assay Reagent, Pierce) and adjusted to $100 \mu \mathrm{g} / \mathrm{ml}$. Finally, the different antigens were stored at $-20^{\circ} \mathrm{C}$ until needed.

\section{ELISPOT assay}

Membrane microplates (PVDF, Millipore) were prewetted with $50 \mu \mathrm{l}$ of ethanol $70 \%$ for $2 \mathrm{~min}$. After washing with phosphate buffer saline (PBS; pH 7.5), plates were coated with $100 \mu \mathrm{l} /$ well of the capture antibody diluted in PBS ( $m A b \lg G 2$ to bovine IFN- $\gamma$, Serotec) at $1 \mu \mathrm{g} / \mathrm{ml}$ and incubated overnight at $4^{\circ} \mathrm{C}$. Plates were then blocked with $300 \mu \mathrm{l} /$ well of phosphate buffer saline Tween 20-bovine serum albumin (PBST-BSA) $1 \%$ and incubated for two hours at room temperature (RT) in agitation.

PBMCs collected from each individual animal were resuspended at a concentration of $2 \times 10^{5}$ cells/well in complete medium (CM) containing Roswell Park Memorial Institute medium (RPMI 1640, Sigma-Aldrich), 10\% bovine foetal serum (BFS, Biochrom AG) and 1\% antibiotic-antimycotic solution (Sigma-Aldrich, St. Louis, USA) andtested in triplicate. PBMCs were stimulated with the mitogen phytohaemagglutinin (PHA) at $6 \mu \mathrm{g} / \mathrm{well}$ and/or different parasitic antigens (CLE, HyA, $\mathrm{HyB}$ and $\mathrm{HyC}$ ) at a final concentration of $100 \mu \mathrm{g} / \mathrm{ml}$. Optimal concentrations of antigens and mitogen were established in previous studies [10].

Control wells contained complete medium only (CM background control), CM plus cells (cell control) or CM plus cells and mitogen (mitogen control). Plates were incubated at $37^{\circ} \mathrm{C}$ in $5 \% \mathrm{CO}_{2}$ for $24 \mathrm{~h}$. Then, the cells were aspirated and wells were rinsed four times with PBST $0.01 \% ; 100 \mu \mathrm{l} /$ well of the secondary biotinylated antibody ( $\mathrm{mAb} \lg \mathrm{g} 2$ to bovine IFN- $\gamma$, Serotec) diluted in PBS at $1 \mu \mathrm{g} / \mathrm{m} /$ were added, and plates were incubated for $2 \mathrm{~h}$ at $\mathrm{RT}$ in agitation. In order to reduce the background, the secondary antibody was filtered through a $0.22 \mu \mathrm{m}$ pore size filter (Millex ${ }^{\oplus}-\mathrm{GP}$, Millipore). Alkaline phosphatase (Sigma-Aldrich) was used as streptavidin conjugate at 1:1000 in Tris buffer saline (TBS) pH8 and colour was developed using 5-bromo-4-chloro-3-indolyl-phosphate, nitro blue tetrazolium (BCIP-NBT, Sigma-Aldrich) as chromogenic substrate. Finally, plates were rinsed with distilled water and let dried completely before analysis. The number of spots/ well was counted manually under a stereomicroscope. Scores from 0 to 5 were established using the following criteria: (0) no spots; (1) less than 50 spots/well; (2) 50-100 spots/well; (3) 100-200 spots/well; (4) 200-400 spots/well; (5) more than 400 spots/well.

\section{ELISA assay}

Parallel cultures, using the same conditions than in the ELISPOT, were performed in uncoated 96-well flat-bottomed cell culture plates (Deltalab). Cell culture supernatants were removed after plate centrifugation, and the presence of IFN- $\gamma$ 
was tested by a sandwich ELISA using a previously described method [6]; the bovine specific IFN- $\gamma$ antibodies employed were the same used in the ELISPOT test.

\section{Statistical analysis}

All statistical tests were performed using Statistical package. Student $t$ test for dependent samples was conducted to investigate the presence of significant differences between PHA stimulated and non-stimulated cultures $(P<0.05)$. Student $t$ test for independent samples was employed to find significant differences between cultures from both Hypoderma sensitized and non-sensitized animals $(P<0.05)$.

\section{Results}

Determination of IFN- $\gamma$ secreting PBMCs by ELISPOT Figure 1 shows the effect of the mitogen PHA and different $H$. lineatum antigens on the number of IFN- $\gamma$-SC. Spontaneous secretion was observed in mitogen unstimulated cultures, although the number of IFN- $\gamma$-SC was higher in non-sensitized PBMC. The stimulation with the mitogen PHA increased the number of IFN- $\gamma$-SC in both sensitized and non-sensitized PBMC cultures, with a more pronounced effect in the former. The incubation of PBMC with Hypoderma antigens reduced the number of IFN- $\gamma-\mathrm{SC}$ in both groups. In previously sensitized cultures, the highest reduction in the number of IFN- $\gamma-S C$ was caused by CLE, followed by HyB and HyA. In contrast, HyB was the fraction with major immunosuppressive effect in non-sensitized cultures, followed by CLE and HyA; HyC barely affected the number of IFN- $\gamma$-SC in both groups. Nevertheless, no significant differences $(P>0.05)$ were detected in response to stimulation with the mitogen and/or the antigens, even in

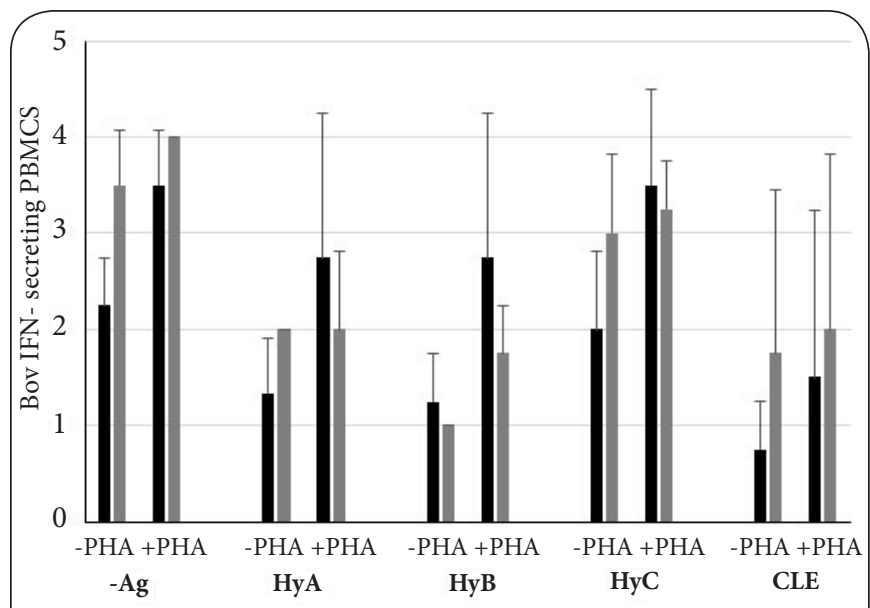

Figure 1. IFN- $\gamma$ secreting cells detected by ELISPOT in bovine PBMCs stimulated with $H$. lineatum antigens. Cells from non-sensitized $(\square)$ and sensitized $(\bullet)$ cattle were incubated in absence (-PHA) and presence (+PHA) of the mitogen PHA. Results are presented as the average and standard deviation. Axis y: Score 0: no spots. Score 1: $<50$ spots/well. Score 2: 50100 spots/well. Score 3: 100-200 spots/well. Score 4: 200-400 spots/well. Score 5: $>400$ spots/well. cultures from previously sensitized animals.

\section{Determination of IFN- $\gamma$ secretion in cell culture supernatants by sandwich ELISA}

Figure 2 shows the effect of the mitogen PHA and different $H$. lineatum antigens on IFN- $\gamma$ levels from culture supernatants using a sandwich ELISA. As occurred with the ELISPOT, the spontaneous secretion of IFN- $\gamma$ was higher in PBMC from naïve animals; in contrast, the stimulatory effect of the PHA was higher in previously sensitized cultures. However, these differences were not significant $(P>0.05)$.

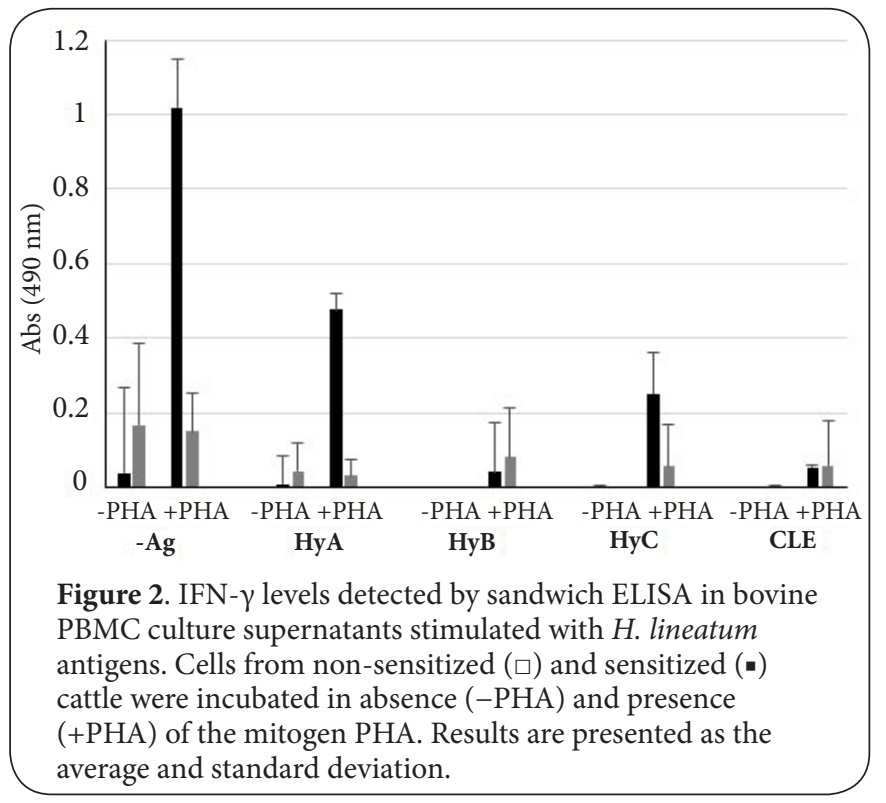

The addition of larval antigens reduced IFN- $\gamma$ levels in both groups of cultures, but the differences were only significant in previously sensitized PBMC cultures ( $\mathrm{HyA}, \mathrm{P}=0.030$; $\mathrm{HyB}$, $\mathrm{P}=0.044 ; \mathrm{HyC}, \mathrm{P}=0.045 ; \mathrm{CLE}, \mathrm{P}=0.030$ ). IFN- $\gamma$ levels were very low in no mitogen-stimulated cultures, where as IFN- $\gamma$ levels were below the detection limit of the test $(1 \mathrm{ng} / \mathrm{ml})$ in nonsensitized cultures stimulated with HyB and CLE. In general, HyA was the antigen showing the least effect on IFN- $\gamma$ secretion, where as CLE was the most immunosuppressive fraction in previously sensitized cultures and $\mathrm{HyB}$ in non-sensitized ones.

The frequencies of IFN- $\gamma-\mathrm{SC}$ could not be correlated with the levels of secreted IFN- $\gamma$ because the latter were often below the detection limit of the ELISA.

\section{Discussion}

Spontaneous secretion of IFN- $\gamma$ was detected in all unstimulated cultures by both techniques, being higher in cultures from non-infested calves, in which IFN- $\gamma$ is secreted by cells of the innate immune system $[11,12]$. Innate IFN- $\gamma$ production is mainly found in young animals, although older animals may also respond in a similar way [13]. 
According to previous in vitro studies [10], the addition of Hypoderma antigens has a suppressive effect on IFN- $\gamma$ secretion. These results suggest that cattle infested by Hypoderma under natural conditions display a significant reduction of IFN- $\gamma$-SC, which may contribute to larval survival in the host.

The number of antigen-specific $T$ cells is frequently very low ex vivo; in such situations, in vitro T cell expansion strategies, as the addition of a mitogen, are needed. The stimulation of PBMC cultures with the mitogen PHA enhanced the frequency of IFN- $\gamma$-SC, especially in previously sensitized cultures. In this sense, cattle repeatedly exposed to Hypoderma presented a more intense cellular response to the antigens and mitogens [4] and acquire a certain degree of resistance to this parasite that results in fewer warbles on their back. The subpopulation of PBMC associated with the in vitro proliferative response to PHA has been shown to have characteristics of T cells which are known to be responsible for cell-mediated immune responses [14].

Hypodermin B was the fraction that most reduced the secretion of IFN- $\gamma$ in non-sensitized cultures and, in general, the HyA was the antigen with minor suppressive effect on IFN- $\gamma$ secretion. These findings contrast with previous studies that reported that HyA induced a significant elevation of IFN- $\gamma$ production by bovine PBMC [10], being the antigen that most inhibited proliferative responses to themitogens $[2,15,16]$. By contrast, CLE, composed by a mixture of the three fractions, showed the strongest suppressor effect on IFN- $\gamma$ secretion in antigen-sensitized cultures. This immune suppressive effect of CLE in mitogen-stimulated PBMC cultures from naïve and previously sensitized cattle has been previously reported [10].

Hypoderm in $\mathrm{C}$ barely affected to the synthesis of IFN- $\gamma$ in all PBMC cultures. These results coincide with other authors $[10,17]$, who proved that $\mathrm{HyC}$ did not show proliferative, cytostatic or toxic activity on bovine lymphocyte cultures. Furthermore, it was demonstrated that the administration of $\mathrm{HyC}$ to previously Hypoderma-infested and uninfested cattle presented no detectable effects on cellular and humoral responses [17].

The high sensitivity of the ELISPOT allowed the determination of IFN- $\gamma$-SC frequencies in non-stimulated cultures, where as the sandwich ELISA has proven to be ineffective in detecting IFN- $\gamma$ levels in parallel culture supernatants. Those results confirm the ability of the ELISPOT to accurately determine the frequency of IFN- $\gamma$-SC in ex vivo PBMCs without the need for extensive restimulation in vitro with antigen or mitogen over long periods of time.

However, the ELISPOT also presents some inconvenient, since itis more time consuming and expensive than the ELISA. Moreover, ELISPOT showed a noticeable variability in the overall reactivity of PBMCs obtained from different donor animals. That deviation may be due to differences in PBMC activation status or simply to the variation expected between animals. It should be considered that even a slight increase in the number of secreting cells becomes detectable with this technique. Previous investigations reported that immune responses to antigen and mitogenic stimulation were extremely variable between animals, especially in the reinfested ones [8].

\section{Conclusion}

The ELISPOT assay has an unsurpassed sensitivity to detect low frequency antigen-specific T cells secreting effector molecules such as cytokines. The secreted cytokine is captured by the antibodies coated on the ELISPOT plates, avoiding their diffusion and dilution on the supernatant, as occurs in the ELISA [8].

Further studies should be performed in order to detect cells secreting other cytokines such as IL-10 or IL-4, leading to a better understanding of the mechanisms of susceptibility or resistance to Hypoderma.

\section{Competing interests}

The authors declare that they have no competing interests.

\section{Authors' contributions}

\begin{tabular}{|l|c|c|c|c|c|c|c|}
\hline Authors' contributions & EC & CL & PD & APC & MPM & PDB & RP \\
\hline Research concept and design & $\checkmark$ & -- & -- & -- & -- & $\checkmark$ & $\checkmark$ \\
\hline Collection and/or assembly of data & $\checkmark$ & $\checkmark$ & $\checkmark$ & $\checkmark$ & $\checkmark$ & -- & $\checkmark$ \\
\hline Data analysis and interpretation & $\checkmark$ & $\checkmark$ & -- & -- & -- & $\checkmark$ & $\checkmark$ \\
\hline Writing the article & $\checkmark$ & -- & -- & - & -- & -- & $\checkmark$ \\
\hline Critical revision of the article & -- & $\checkmark$ & $\checkmark$ & $\checkmark$ & $\checkmark$ & $\checkmark$ & -- \\
\hline Final approval of article & $\checkmark$ & $\checkmark$ & $\checkmark$ & $\checkmark$ & $\checkmark$ & $\checkmark$ & $\checkmark$ \\
\hline Statistical analysis & $\checkmark$ & $\checkmark$ & -- & -- & -- & -- & -- \\
\hline
\end{tabular}

\section{Acknowledgement}

This study was supported by the Research Project AGL-2009-08939 and by a grant for Consolidating and Structuring Competitive Research Groups (Xunta de Galicia CN2012/326). The authors also thank the Xunta de Galicia government for pre-doctoral grant to E. Cabanelas.

\section{Publication history}

Editor: Franz-Josef Kaup, German Primate Center, Germany. Received: 15-Feb-2016 Final Revised: 11-Mar-2016 Accepted: 25-Mar-2016 Published: 07-Apr-2016

\section{References}

1. Boulard C. [Preliminary study of crude collagenase extracted from the 1st stage larva of Hypoderma lineatum (de Villers)]. C R Acad Sci Hebd Seances Acad Sci D. 1970; 270:1349-51. I Article I PubMed

2. Moire N, Nicolas-Gaulard I, Le Vern Y and Boulard C. Enzymatic effect of hypodermin A, a parasite protease, on bovine lymphocyte membrane antigens. Parasite Immunol. 1997; 19:21-7. | Article | PubMed Abstract | PubMed FullText

3. Gingrich RE. Acquired resistance to Hypoderma lineatum: comparative immune response of resistant and susceptible cattle. Vet Parasitol. 1982; 9:233-42. | Article | PubMed

4. Baron RW and Weintraub J. Lymphocyte responsiveness in cattle previously infested and uninfested with Hypoderma lineatum (de Vill.) and H. bovis (L.) (Diptera: Oestridae). Vet Parasitol. 1987; 24:285-96. | Article I PubMed

5. Schoenborn JR and Wilson CB. Regulation of interferon-gamma during 
innate and adaptive immune responses. Adv Immunol. 2007; 96:41-101. | Article | PubMed

6. Dacal V, Colwell DD, Lopez C, Perez V, Vazquez L, Cienfuegos S, Diaz P, Morrondo P, Diez-Banos P and Panadero R. Local and systemic cytokine responses during larval penetration in cattle experimentally infested with Hypoderma lineatum (Diptera: Oestridae). Vet Immunol Immunopathol. 2009; 131:59-64. | Article | PubMed

7. Vazquez L, Dacal V, Lopez C, Diaz P, Morrondo P, Diez-Banos P and Panadero R. Antigen-specific antibody isotypes, lymphocyte subsets and cytokine profiles in cattle naturally infested by Hypoderma sp. (Diptera: Oestridae). Vet Parasitol. 2012; 184:230-7. | Article | PubMed

8. Lehmann PV and Zhang W. Unique strengths of ELISPOT for T cell diagnostics. Methods Mol Biol. 2012; 792:3-23. | Article | PubMed

9. Czerkinsky C, Andersson G, Ekre HP, Nilsson LA, Klareskog L and Ouchterlony O. Reverse ELISPOT assay for clonal analysis of cytokine production. I. Enumeration of gamma-interferon-secreting cells. J Immunol Methods. 1988; 110:29-36. | Article | PubMed

10. Panadero R, Dacal V, Lopez C, Vazquez L, Cienfuegos S, Diaz P, Morrondo $P$ and Diez-Banos P. Immunomodulatory effect of Hypoderma lineatum antigens: in vitro effect on bovine lymphocyte proliferation and cytokine production. Parasite Immunol. 2009; 31:72-7. | Article | PubMed

11. Townsend J, Duffus WP and Williams DL. Immune production of interferon by cultured peripheral blood mononuclear cells from calves infected with BHV1 and PI3 viruses. Res Vet Sci. 1988; 45:198-205. | Article | PubMed

12. Olsen I and Storset AK. Innate IFN-gamma production in cattle in response to MPP14, a secreted protein from Mycobacterium avium subsp. Paratuberculosis. Scand J Immunol. 2001; 54:306-13. | Article | PubMed

13. McDonald WL, Ridge SE, Hope AF and Condron RJ. Evaluation of diagnostic tests for Johne's disease in young cattle. Aust Vet J. 1999; 77:113-9. | Article | PubMed

14. Nicolas-Gaulard I, Moire $N$ and Boulard $C$. Effect of the parasite enzyme, hypodermin A, on bovine lymphocyte proliferation and interleukin-2 production via the prostaglandin pathway. Immunology. 1995; 85:160-5. | PubMed Abstract | PubMed FullText

15. Fisher WF, Pruett JH, Howard VM and Scholl PJ. Antigen-specific lymphocyte proliferative responses in vaccinated and Hypoderma lineatum-infested calves. Vet Parasitol. 1991; 40:135-45. | Article | PubMed

16. Chabaudie $\mathrm{N}$ and Boulard C. Effect of hypodermin A, an enzyme secreted by Hypoderma lineatum (Insect Oestridae), on the bovine immune system. Vet Immunol Immunopathol. 1992; 31:167-77. | Article I PubMed

17. Chabaudie $\mathrm{N}$ and Boulard $\mathrm{C}$. In vitro and ex vivo responses of bovine lymphocytes to hypodermin C, an enzyme secreted by Hypoderma lineatum (insect oestridae). Vet Immunol Immunopathol. 1993; 36:15362. | Article | PubMed

\section{Citation:}

Cabanelas E, Lopez C, Diaz P, Perez-Creo A, Morrondo MP, Diez-Banos P and Panadero R. Evaluation of IFN- $\gamma$ production in bovine hypodermosis using ELISPOT and ELISA. Vet Med Anim Sci. 2016; 4:2.

http://dx.doi.org/10.7243/2054-3425-4-2 